\title{
A UNIPAMPA NO CONTEXTO ATUAL DA EDUCAÇÃO SUPERIOR
}

\author{
Dáfni Fernanda Zenedin Marchioro ${ }^{1}$ \\ Daniel Luiz Nedel ${ }^{2}$ \\ Dulce Mari da Silva Voss ${ }^{3}$ \\ Edson Massayuki KaKunO ${ }^{4}$ \\ Gabriela Dalcin da Fonseca ${ }^{5}$ \\ Margarida Maria Rodrigues Negrão ${ }^{6}$ \\ Valesca Brasil Irala ${ }^{7}$ \\ Vera Lúcia Duarte Ferreira ${ }^{8}$
}

Recebido em: 10/10/ 07

Avaliado em: 26/11/07

1 Professora da Universidade Federal de Pelotas no campus da UNIPAMPA/Bagé, doutora em Física, atuando nos Cursos de Licenciatura em Matemática e Engenharia de Alimentos.

2 Professor da Universidade Federal de Pelotas no campus da UNIPAMPA/Bagé, doutor em Física, atuando nos Cursos de Licenciatura em Matemática e Engenharia de Energias Renováveis e Ambientes.

3 Professora da Universidade Federal de Pelotas no campus da UNIPAMPA/Bagé, Mestre em Educação, atuando nos Cursos de Licenciatura em Matemática, Licenciatura em Letras, Licenciatura em Química e Licenciatura em Física.

4 Professor da Universidade Federal de Pelotas no campus da UNIPAMPA/Bagé, doutor em Física, atuando nos Cursos de Licenciatura em Física e Engenharias.

5 Técnica em Assuntos Educacionais da Universidade Federal de Pelotas no campus da UNIPAMPA/ Bagé, Licenciada em Letras.

6 Professora da Universidade Federal de Pelotas no campus da UNIPAMPA/Bagé, doutora em Física, atuando nos Cursos de Licenciatura em Matemática, Licenciatura em Física e Engenharia de Energias Renováveis e Ambientes.

7 Professora da Universidade Federal de Pelotas no campus da UNIPAMPA/Bagé, doutoranda em Letras, atuando nos Cursos de Licenciatura em Letras Espanhol e Licenciatura em Letras Inglês.

8 Professora da Universidade Federal de Pelotas no campus da UNIPAMPA/Bagé, Mestre em Matemática, atuando no Curso de Licenciatura em Matemática.

Resumo: Nesse artigo analisamos o processo de implantação da Universidade Federal do Pampa como parte das políticas públicas nacionais de expansão do acesso à educação superior e seus significados, a partir de um estudo realizado por um grupo de docentes dessa universidade quanto ao diagnóstico da realidade local. Abordamos duas questões fundamentais: a relevância social da construção da universidade no atual contexto local de estagnação econômica e cultural e a questão do desenvolvimento como elemento transformador dessa realidade. Nosso objetivo é contribuir no processo histórico do qual somos parte.

Palavras-Chave: Universidade Federal do Pampa; educação superior; relevância social; desenvolvimento. 
Dáfni Fernanda Zenedin Marchioro, Daniel Luiz Nedel,

Dulce Mari da Silva Voss, Edson Massayuki Kakuno, Gabriela Dalcin da Fonseca,

Margarida Maria Rodrigues Negrão, Valesca Brasil Irala e Vera Lúcia Duarte Ferreira

The Unipampa in the current context of higher education

\begin{abstract}
This article presents a study developed by a group of professors in which we analyze the process of implementation of the Pampa Federal University as part of the national public policies for the expansion of access to higher education. The study includes a diagnosis of the local educational reality and deals with two main topics: the social relevance of creating this new university in the present local context characterized by cultural and economic stagnation and the role of development as a transforming element of such reality. The purpose of the investigation was to contribute to the historical process in which we are involved.
\end{abstract}

Key Words: Universidade Federal do Pampa; higher education; Southern region of Brazil; social relevance; development.

\title{
Introdução
}

A criação da Fundação Universidade Federal do Pampa, cujo Projeto de Lei encontra-se em tramitação no Congresso Nacional, faz parte das políticas públicas federais que buscam atender a necessidade de expansão da rede de educação superior, mediante a possibilidade de novos projetos de desenvolvimento da região sul do Rio Grande do Sul.

A Portaria MEC/SESU 225, de 16 de março de 2007, instituiu a Comissão de Implantação da futura Universidade Federal do Pampa, que vem promovendo encontros e discussões com a comunidade acadêmica para o delineamento e organização estrutural e pedagógica da Unipampa.

A participação dos docentes, técnico-administrativos, discentes e comunidade civil organizada nesse processo torna-se uma importante via de interlocução, aproximação e construção da identidade da Unipampa pelos sujeitos sociais que assumiram o desafio de efetivar tal projeto.

No dia 04 de maio de 2007, foi realizado o I Seminário de Planejamento Unificado da Unipampa, na sede do Campus da Unipampa em Bagé, o qual foi coordenado pelos membros da Comissão de Implantação e contou com a participação de representantes docentes, discentes e técnicoadministrativos dos dez campi da universidade. Nesse seminário foram organizados oito grupos de trabalho para analisar e propor formas de organização e gestão da Unipampa.

O grupo 3 foi incumbido de analisar e propor encaminhamentos quanto à concepção de formação e projeto acadêmico que, conforme orientações da Comissão de Implantação, inclui estudos e proposições acerca do Projeto Político Pedagógico Institucional, Projetos Político Pedagógicos dos Cursos, Núcleos Pedagógicos de Suporte, Mobilidade Docente e Discente. 
Para viabilizar as suas ações, no Campus da Unipampa em Bagé, o grupo 3 foi constituído por alguns docentes que se inseriram a ele de forma voluntária, sem necessariamente fazer parte das representações oficiais dos cursos da unidade, promovendo-se reuniões semanais de discussão e organização do trabalho proposto. Nesse documento procuramos expor os estudos, as idéias e propostas analisadas por esse grupo no intuito de contribuir para o debate democrático e a construção da identidade da Unipampa que atenda as reais expectativas e necessidades dos sujeitos e da comunidade envolvidos nesse projeto.

Partimos do pressuposto que o delineamento da identidade institucional da Unipampa seja tecido através de uma rede de relações humanas, sociais e profissionais fundadas em múltiplas situações de diálogo entre os diferentes sujeitos que participam desse projeto, tendo presente que,

Ao fundar-se no amor, na humildade, na fé nos homens, o diálogo se faz uma relação horizontal, em que há confiança de um no outro. Não existe tampouco diálogo sem esperança, sem um pensar verdadeiro, um pensar que percebe a realidade como processo de luta pelo ser mais. Essa busca não se faz no isolamento, mas na comunicação entre os homens (FREIRE, 1987, p. ).

O diálogo alicerçado no respeito mútuo e na cooperação deve ser a ferramenta básica para nosso trabalho, compreendendo-se que a diversidade de pontos de vista, práticas e posturas são constitutivas da natureza humana. Conviver sem arrogância significa abrir caminhos para o diálogo.

A interação dos diferentes sujeitos partícipes do processo de construção da Unipampa propiciará a costura da universidade que queremos e assumiremos enquanto projeto social e educativo.

\section{As políticas educacionais e o projeto da UNIPAMPA}

Durante a década de 90, vivemos em nosso país um processo de restrição das políticas federais de acesso a Educação Superior imposta pelas ações neoliberais de redução do chamado "déficit público" que cortou orçamentos e concursos. Ao mesmo tempo, a oferta da Educação Superior pela iniciativa privada alcançou patamares elevados.

As políticas neoliberais e as estratégias privatizantes levadas a efeito, naquele momento, tinham como um de seus objetivos fundamentais apa- 
Dáfni Fernanda Zenedin Marchioro, Daniel Luiz Nedel,

Dulce Mari da Silva Voss, Edson Massayuki Kakuno, Gabriela Dalcin da Fonseca,

Margarida Maria Rodrigues Negrão, Valesca Brasil Irala e Vera Lúcia Duarte Ferreira

gar do horizonte cultural a dimensão da educação como direito constitucional público e inalienável, inculcando no imaginário social a concepção da educação como serviço e bem de consumo.

Em outras palavras, o neoliberalismo precisa - em primeiro lugar, ainda que não unicamente - despolitizar a educação, dando-lhe um novo significado como mercadoria para garantir, assim, o triunfo de suas estratégias mercantilizantes e o necessário consenso em torno delas (GENTILI, 1994, p. 244-5).

Sendo assim, as reformas ocorridas nas políticas nacionais da Educação Superior, desencadeadas na década de 90, inauguraram um processo de mudança na própria concepção da universidade brasileira. De uma instituição social, a universidade passou a ser concebida como uma organização social, tendo o mercado, e não mais a sociedade como sua referência reguladora.

Saviani (1999) anuncia os princípios norteadores de uma política educacional que, em contraposição às ações neoliberais, estivessem desatrelada da economia capitalista e dimensionasse os recursos em função das necessidades de atendimento, entendendo que,

A defesa do ensino público e gratuito e a reivindicação por mais verbas para a educação constituem um aspecto da luta pela valorização da política social em relação à política econômica (SAVIANI, 1999, p. 127).

Nos tempos atuais, alguns sinais de rompimento com as políticas de redução do acesso à Educação Superior pública começam a surgir.

O Plano Nacional de Educação (Lei 10.172/2001) aponta nessa direção ao demonstrar a insuficiência de vagas nas universidades para atender os egressos do Ensino Médio.

O nível de acesso dos jovens brasileiros na faixa etária dos 18 aos 24 anos à educação superior é um dos mais baixos do continente latino-americano $(9 \%)$. A proporção de estudantes nas instituições públicas reduziuse drasticamente nos últimos dez anos, representando hoje menos de 1/3 do total, já que o peso da matrícula das instituições privadas tornou-se o mais alto da América Latina (70 a 88,9\%).

Portanto, o grande desafio da Educação Superior hoje encontra-se na necessidade de expansão do acesso ao sistema público que, além da ampli- 
ação da oferta, garanta efetivamente a qualidade e a eqüidade através da promoção de políticas nacionais capazes de incluir a grande parcela da população brasileira, que até então esteve à margem desse sistema.

Isso significa abrir novas possibilidades para o ingresso das classes populares e grupos étnicos excluídos na educação superior, processo esse que contemple também a organização de projetos pedagógicos e currículos acadêmicos que atendam as necessidades dessa população.

Há que se romper também com a centralização territorial da educação superior em nosso país, promovendo-se políticas públicas de interiorização das universidades para que essas venham a constituírem-se como projetos alternativos à situação de estagnação social, econômica e cultural existentes nas regiões brasileiras periféricas.

Acreditamos que a Universidade Federal do Pampa (Unipampa) poderá efetivar-se enquanto uma alternativa à situação de estagnação da região sul do RS, à medida que sua estrutura, organização e gestão sejam definidas em prol de um projeto social, econômico e cultural apropriado às reais necessidades regionais e locais.

Cabe aqui traçar um breve panorama da realidade regional, buscando conhecer as raízes históricas desse contexto.

Segundo Chelotti (2006), a campanha gaúcha é um espaço regional inserido na região de fronteira brasileira com o Uruguai e Argentina, que sofreu ao longo das últimas décadas, principalmente a partir de meados da década de 80 , um profundo processo de perda de dinamismo econômico, resultado das dificuldades de inserção nos ciclos de expansão da economia brasileira. Há mais de meio século, portanto, a região que já foi palco de empreendimentos pioneiros no Estado, defronta-se com dificuldades que têm colocado obstáculos no seu desenvolvimento econômico e social.

A população da região sul do RS já representou mais da metade do Estado na virada do século XVIII, hoje não chega a um quarto. Sua participação na produção industrial do Estado, que já foi de $35 \%$ na década de 1930; na década de 1990 se aproximou de apenas $10 \%$ e a participação no PIB do Estado, que já esteve entre 38\% e 39\% no final da década de 1930; chegou em torno de $17 \%$ no final da década de 1990. Ainda em termos comparativos, destaca-se que nas regiões norte e nordeste do estado, $94 \%$ dos municípios estão situados nas faixas média e alta do IDS (Índice de Desenvolvimento Social), ao passo que, na metade sul, $87 \%$ deles estão nas faixas média e baixa. Assim, verifica-se claramente uma grande dualidade sócio-territorial no Rio Grande do Sul quanto aos indicadores 
Dáfni Fernanda Zenedin Marchioro, Daniel Luiz Nedel,

Dulce Mari da Silva Voss, Edson Massayuki Kakuno, Gabriela Dalcin da Fonseca,

Margarida Maria Rodrigues Negrão, Valesca Brasil Irala e Vera Lúcia Duarte Ferreira

socioeconômicos. Isso ocorre porque, embora possuindo uma área territorial semelhante, a região sul do RS possui apenas $15,35 \%$ dos municípios e apenas $22,63 \%$ do total da população gaúcha. Esses indicadores socioeconômicos estão muitos associados aos condicionantes históricos, como a forma de apropriação desse espaço, que se deu por meio da doação de sesmarias, com baixíssima densidade demográfica e também pela concentração dos meios de produção nas mãos da classe latifundiária pastoril.

No final da República Velha algumas transformações passariam a redefinir a economia brasileira, sendo que gradativamente ocorreu a substituição das economias regionais em proveito de uma economia de nível nacional com a criação, a expansão e a hegemonia do capital industrial, acirrando as diferenças entre região norte e sul do RS.

As desigualdades regionais acentuadas trouxeram à tona os conflitos sociais decorrentes da estrutura fundiária ainda assentada no latifúndio monocultor. Na década de 90, surgem vários acampamentos e assentamentos do Movimento Sem-Terra na campanha gaúcha, denunciando as mazelas das desigualdades sociais e regionais.

Vemos assim, que a transformação da realidade de estagnação econômica da região sul do RS passa, necessariamente, pela formação de um novo contexto econômico, social e cultural que rompa com a estrutura histórica que deu origem as atuais dificuldades. Há que se recriar o projeto de desenvolvimento da região sul do RS, de forma a articular sua população e a produção local com um projeto nacional voltado para a conquista de uma sociedade mais justa e igualitária.

\section{Unipampa: relevância social e projeto de desenvolvimento}

Entendendo que todo planejamento deve partir de um diagnóstico da realidade abordada, levantamos alguns dados através da realização de um questionário respondido por acadêmicos(as) dos Cursos da Unipampa, Campus de Bagé, no intuito de contribuir no processo de discussão e definição do projeto institucional dessa universidade.

A questão do acesso e da qualidade da educação superior está intimamente ligada à sua relevância social, sendo essa uma das nossas categorias de análise dos dados coletados nos questionários.

Observamos que um dos principais fatores que levaram os acadêmicos a ingressar na Unipampa foi por ser uma instituição de educação superior do sistema público federal. 
Gráfico 1 - Fator principal para a escolha do curso

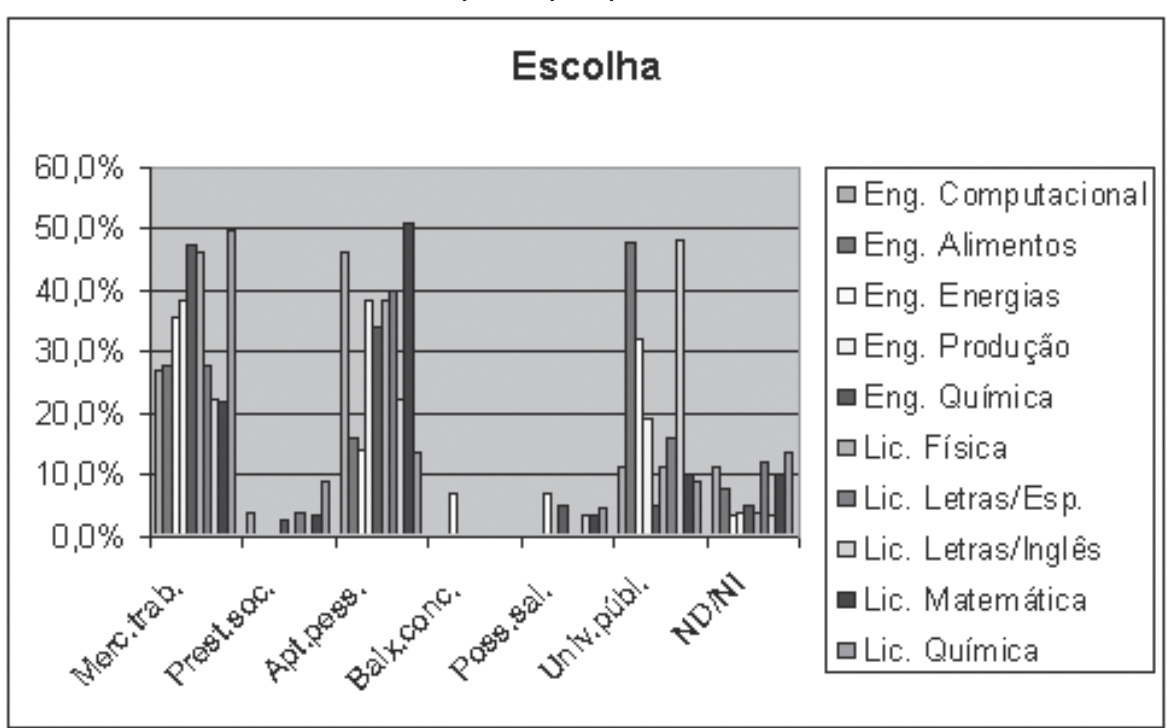

Outro dado que reforça a importância da Unipampa situar-se no sul do RS, refere-se ao fato de que a maioria dos acadêmicos têm como local de origem essa região.

Gráfico 2 - Localidade do Ensino Médio

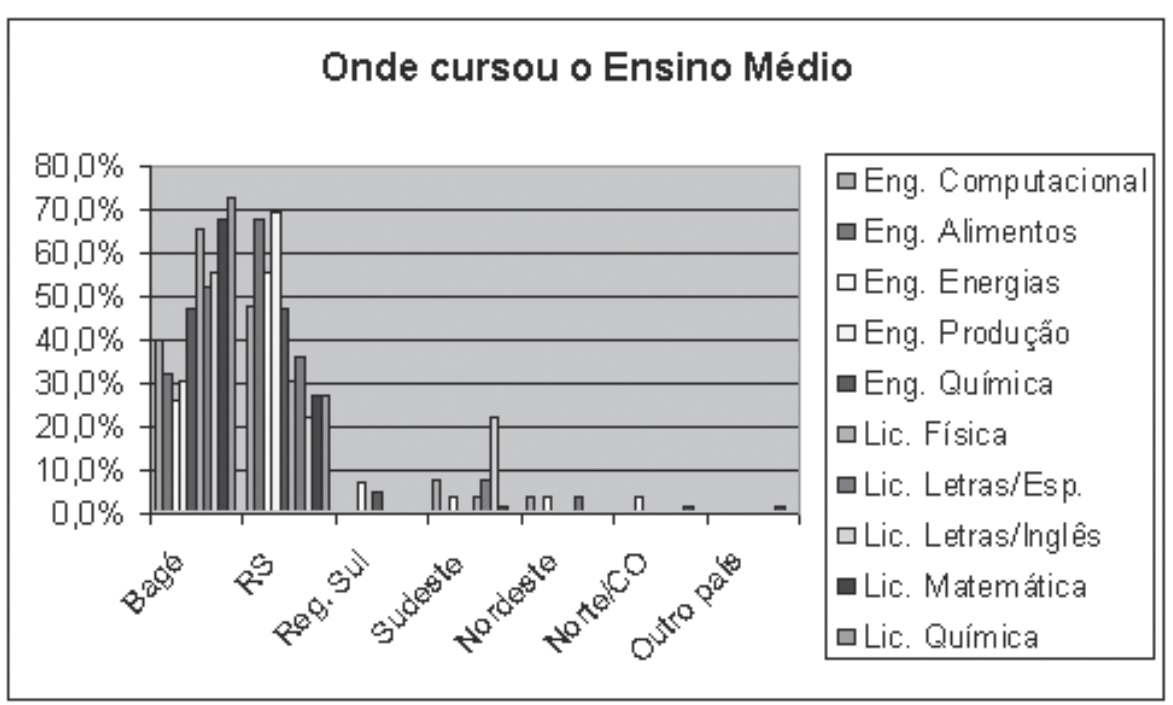


Dáfni Fernanda Zenedin Marchioro, Daniel Luiz Nedel,

Dulce Mari da Silva Voss, Edson Massayuki Kakuno, Gabriela Dalcin da Fonseca,

Margarida Maria Rodrigues Negrão, Valesca Brasil Irala e Vera Lúcia Duarte Ferreira

Gráfico 3 - Ano de conclusão do Ensino Médio

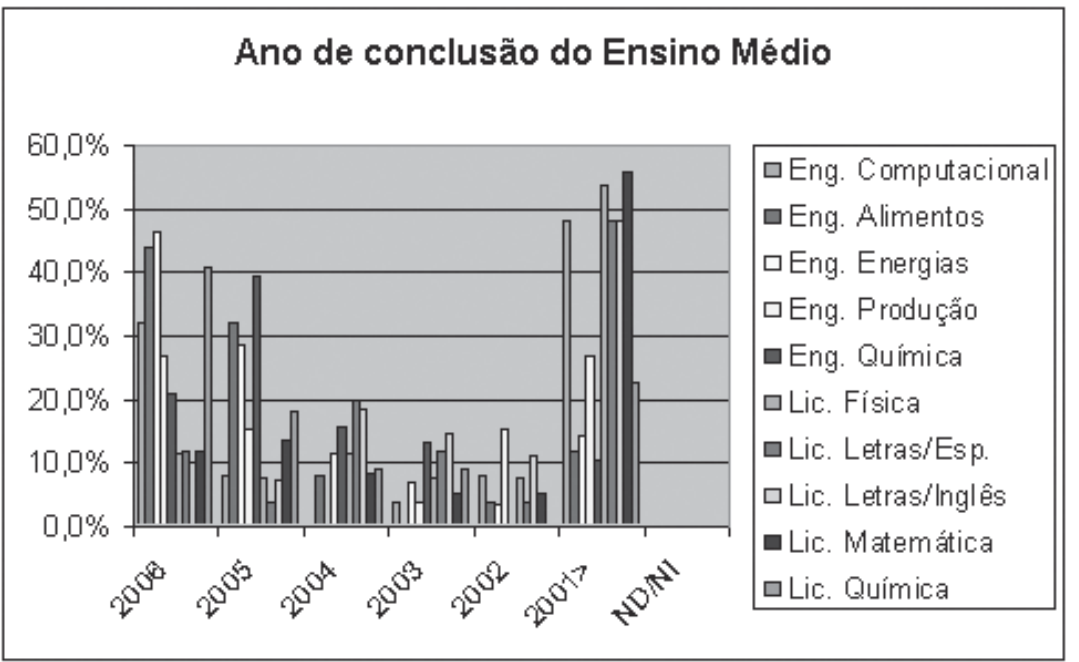

Cabe salientar que esses(as) acadêmicos(as), em sua maioria, são oriundos da escola pública, principalmente da rede estadual de ensino.

\section{Gráfico 4 - Categoria de escola onde cursou o Ensino Médio}

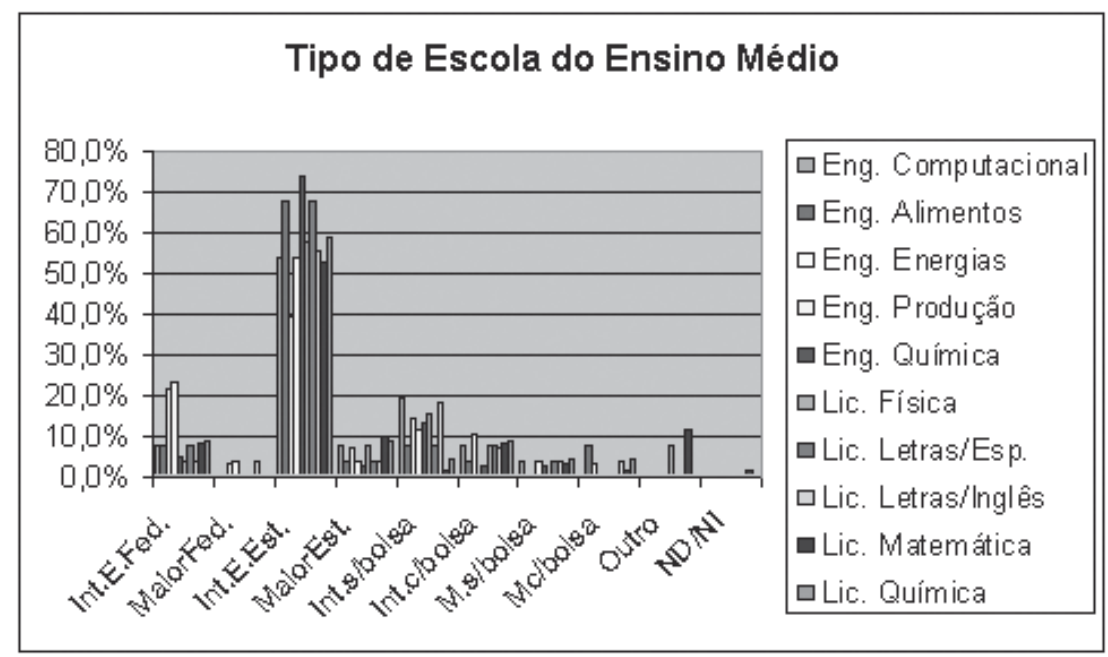

Quanto ao perfil sócio-econômico, vimos que os(as) alunos(as) que cursam a educação superior na Unipampa, provêm, em sua maioria das 
classes populares, com bastante concentração de alunos com renda mensal entre 1 e 5 salários mínimos.

\section{Gráfico 5 - Renda mensal}

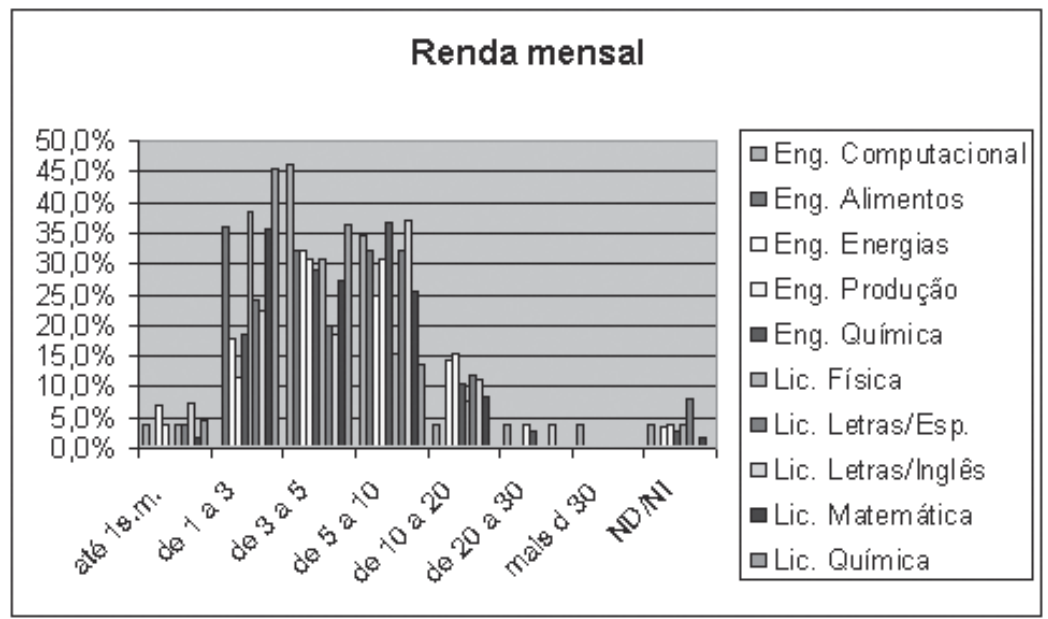

\section{Gráfico 6 - Com quem mora}

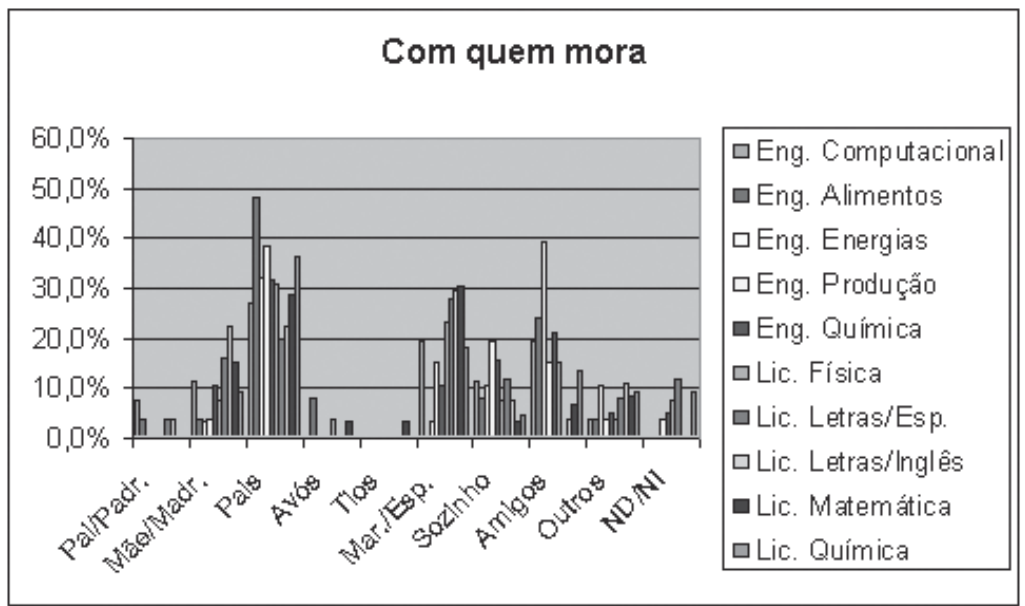

Os dados dos gráficos 6 e 7 reforçam que, em sua maioria, há, no quadro de alunos entrevistados, um grande contingente que depende economicamente da família, o que reforça a expectativa de mudanças em tor- 
Dáfni Fernanda Zenedin Marchioro, Daniel Luiz Nedel,

Dulce Mari da Silva Voss, Edson Massayuki Kakuno, Gabriela Dalcin da Fonseca,

Margarida Maria Rodrigues Negrão, Valesca Brasil Irala e Vera Lúcia Duarte Ferreira

no dos benefícios que lhes proporcionará a universidade pública, já que a grande maioria espera no futuro uma vida financeira e realização pessoal melhor que a dos seus pais.

Gráfico 7 - Participação na vida econômica familiar

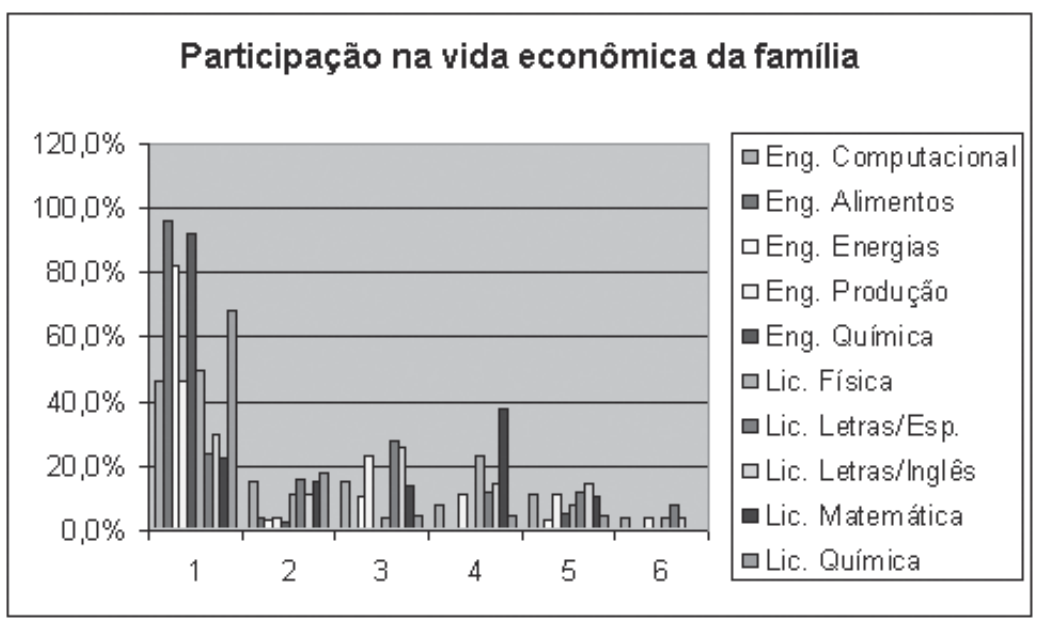

Quanto à questão étnica, percebemos que, no contingente de alunos entrevistados que cursam nossa universidade, ainda é pequeno o número de afrodescendentes e indígenas.

Gráfico 8 - Raça

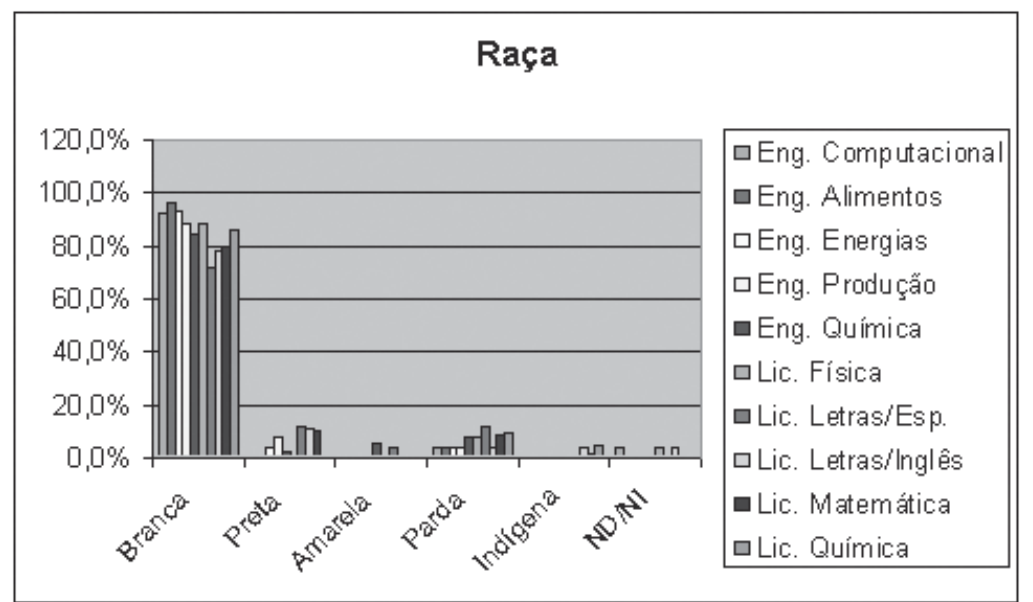


Em comparação aos dados nacionais, retirados do ENADE (Exame Nacional de Desempenho de Estudantes), esse último gráfico revela uma desproporção mais acentuada do que a encontrada em outras categorias antes analisadas, como a renda mensal, participação na vida econômica da família, etc. Em relação à raça, os dados do ENADE apontam um percentual de $68,9 \%$ de alunos declarados brancos, enquanto no questionário realizado na UNIPAMPA, esse índice chega a 85,1\%.

Há que se considerar, no entanto, que, tivemos até agora apenas dois períodos de ingresso de novas turmas na Unipampa; tempo ainda insuficiente para traçar o perfil de nossos estudantes pois, a.universidade ainda não representa uma referência nacional capaz de atrair o interesse de estudantes de outras regiões do país.

Para manter o perfil do corpo discente atual (alunos em sua maioria provenientes da região, originários das classes populares e das escolas públicas), entendemos ser fundamental a adoção de novas políticas de ingresso estudantil na Unipampa que possibilitem a ampliação do acesso a um maior contingente de jovens e adultos provenientes das classes populares e das escolas públicas, indo ao encontro de políticas inclusivas propostas na expansão da educação superior.

Porém, não é suficiente apenas interpretar a expansão do acesso como novas formas de ingresso. A política de mobilidade estudantil depende diretamente das condições de assistência estudantil oferecidas, tais como moradia, transporte, bolsas de estudo e recursos pedagógicos que viabilizem a permanência desses estudantes na universidade e a promoção com o alcance da formação acadêmica de nível superior.

Cabe lembrar que a situação de estagnação econômica em que se encontra a região sul do RS, até o presente momento, tornam precárias as condições de infra-estrutura em termos de habitação, locomoção e demais serviços necessários para acolher um novo contingente populacional (professores, alunos e funcionários) nessas localidades.

Políticas de assistência e mobilidade estudantil podem estar associadas a ações de auto-sustentabilidade que, em contrapartida aos benefícios oferecidos, permita a participação desses acadêmicos em serviços, projetos e ações da própria universidade.

Também é fundamental a articulação entre a universidade e a escola de Educação Básica em termos de projetos e ações que viabilizem o acesso desses educandos à educação superior. 
Dáfni Fernanda Zenedin Marchioro, Daniel Luiz Nedel,

Dulce Mari da Silva Voss, Edson Massayuki Kakuno, Gabriela Dalcin da Fonseca,

Margarida Maria Rodrigues Negrão, Valesca Brasil Irala e Vera Lúcia Duarte Ferreira

Uma segunda categoria de análise refere-se ao projeto de desenvolvimento que fundamenta a Unipampa. Cabe questionar, que projeto institucional poderá melhor servir às necessidade da população da campanha gaúcha? Que políticas darão conta de tornar a Unipampa um projeto alternativo à situação de estagnação regional? Quando proclamamos que o lema da Unipampa é "educar é desenvolver", que significados têm essa prerrogativa?

O projeto da Unipampa representa, sem dúvida, um passo importante rumo à ampliação do acesso à Educação Superior num contexto econômico, social e cultural até então carente de ações estatais.

O projeto de desenvolvimento sobre o qual se assentará a Unipampa não pode restringir-se às expectativas do mercado. Esse tem sido o papel histórico da universidade, formar profissionais para o mercado de trabalho e essa continua sendo uma das maiores expectativas de nossos acadêmi$\cos$.

Gráfico 9 - O que mais espera de um curso universitário

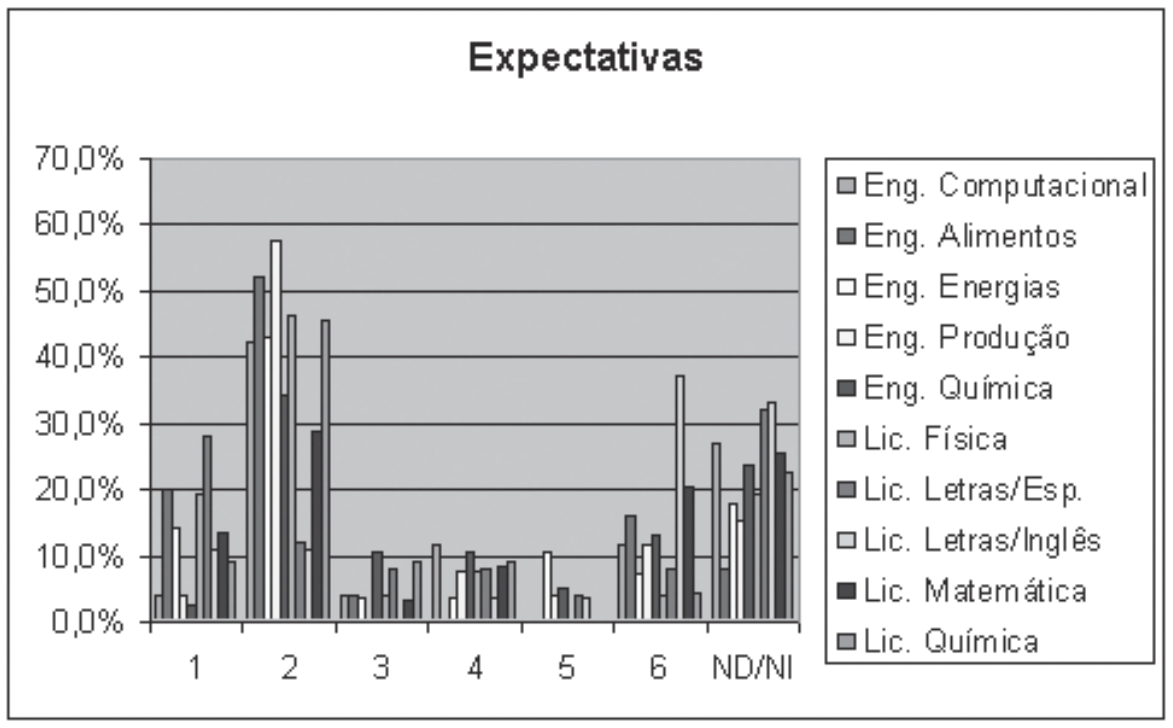

(1) cultura geral ampla; (2) formação para o mercado de trabalho; (3) formação teórica voltada para a pesquisa; (4) formação acadêmica para melhorar a atividade prática; (5) conhecimentos que permitam entender melhor o mundo em que vivemos; (6) conhecimentos que melhorem o nível de instrução. 
Quando 35\% dos acadêmicos afirmam ser o mercado de trabalho o fator principal de motivação para cursar a universidade e, ao mesmo tempo, $60 \%$ afirma que pretende ficar na região e $70 \%$ esperam que a região forneça condições de trabalho, percebemos uma grande contradição frente a realidade presente, sendo que, tal situação possa significar uma grande expectativa em torno da universidade, que venha transformar o contexto atual.

Gráfico 10 - Expectativa de oferta de trabalho na região

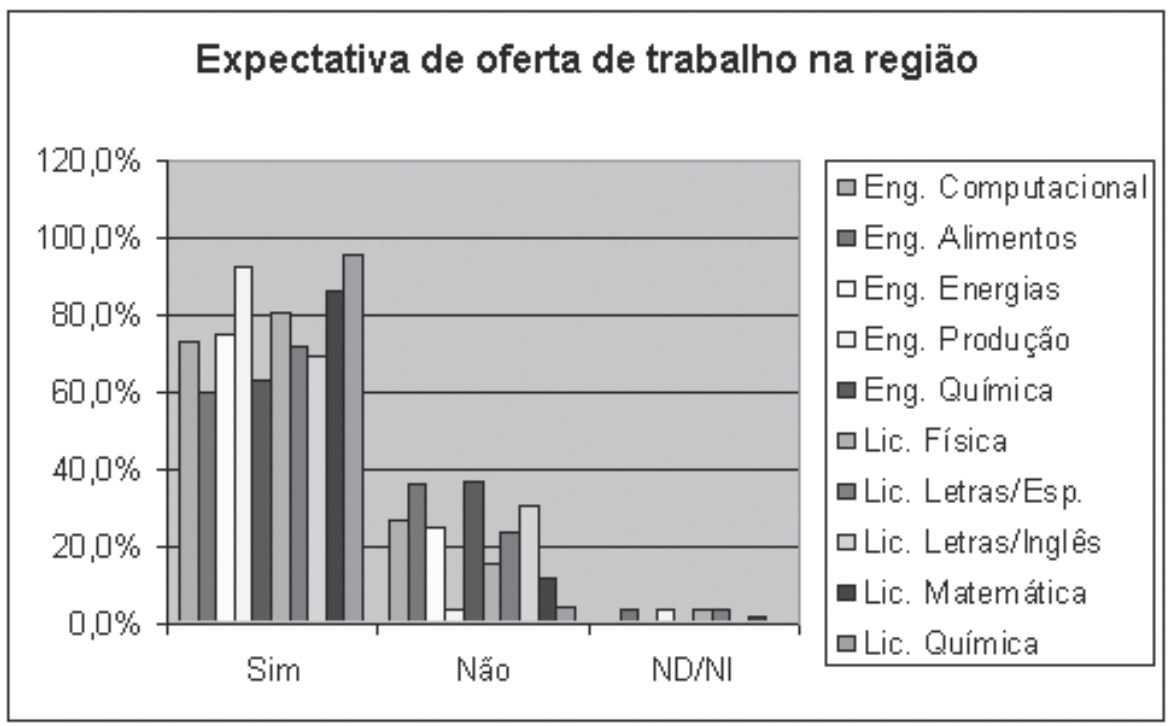

Que consequiências uma universidade fundamentada e organizada sobre o paradigma do mercado trará a região da campanha? Se pensarmos que a universidade deve servir ao mercado, a que demandas da região da campanha estará voltada a universidade?

Entendemos que uma universidade adaptada ao mercado numa região estagnada econômica e socialmente, serviria principalmente aos interesses das oligarquias locais que já concentram o capital em suas mãos, exercendo poder também sobre a produção cultural em termos da pesquisa e extensão desenvolvidas pela universidade. Além do que, os profissionais formados na universidade que tiverem a possibilidade de inseriremse no mercado, provavelmente não permanecerão na região. Dessa forma, 
Dáfni Fernanda Zenedin Marchioro, Daniel Luiz Nedel,

Dulce Mari da Silva Voss, Edson Massayuki Kakuno, Gabriela Dalcin da Fonseca,

Margarida Maria Rodrigues Negrão, Valesca Brasil Irala e Vera Lúcia Duarte Ferreira

a universidade não contribuirá para romper com esse círculo vicioso e com a realidade vigente.

Portanto, a universidade precisa comprometer-se com um projeto de desenvolvimento voltado à conquista de condições mais dignas de vida e trabalho. Um projeto de desenvolvimento social e humano, sustentável e eqüitativo.

Para que a Unipampa possa cumprir o papel estratégico de formação de pesquisadores, educadores e profissionais que, inseridos nesse contexto, poderão ampliar, qualificar e promover ações de desenvolvimento humano e sustentável, cabe salientar a necessidade de investimentos tanto na infra-estrutura, quanto no seu corpo docente e técnico-administrativo, por parte dos órgãos de gestão financeira da universidade.

O debate democrático em torno do papel social que a Unipampa venha a cumprir deve ser ampliado, de forma a extrapolar as necessidades de desenvolvimento econômico e agregando princípios, valores e ações voltadas à formação integral de sujeitos sociais emancipados e éticos.

Cabe a Unipampa, como afirma Panizzi (2007 p. ), "interagir com o mercado mas não fazer dele sua razão de existir". O desenvolvimento e a educação devem estar entrelaçados com mais e melhores oportunidades de formação cultural, nos campos do trabalho, do lazer, das artes, da vida humana nas suas múltiplas manifestações.

\section{Considerações Finais}

O contexto apresentado e analisado neste trabalho mostra que uma universidade com pouca autonomia e sem capacidade de reflexão crítica em torno das suas concepções e práticas pouco ajudará num processo de mudança. É preciso reinventar a universidade e a região, sem perder suas raízes culturais. É preciso mudar as relações de poder que definem o atual cenário de uma realidade social estagnada e desigual.

Ao longo da história, a universidade concebida como instituição social tem sido uma instância legítima de reflexão, por várias vezes contradição, e síntese da sociedade onde está inserida.

Por outro lado, uma organização social tem uma prática determinada por sua instrumentalidade e capacidade de adaptação às demandas do mercado. Uma universidade, concebida dessa forma, têm objetivos particulares e compete com demais organizações que traçaram os mesmos objetivos. 
Portanto, ao desejarmos que a Unipampa seja um elemento novo, precisamos aspirar autonomia crítica sem perder de vista a relação com a sociedade. A universidade deve colaborar para o desenvolvimento humano e sustentável da região, interagindo com a sociedade local e regional, mas guiada por um projeto social global autônomo.

A universidade deve ser um elemento de transformação concebido e realizado por todos sujeitos partícipes do processo: docentes, discentes e comunidade. Devemos nos ater numa educação superior calcada na cidadania, formando sujeitos críticos e autônomos, capazes de reinventar a si mesmos e o mundo em que vivem.

\section{Referências}

CHELOTTI, Marcelo C. Revisitando a questão regional na Campanha Gaúcha: a incorporação de novos elementos no pós 1990. Caminhos da Geografia. Instituto de Geografia UFU, MG, Disponível em: <fev/2006, http// www.is.ufu.br/revista/caminhos.html>.

FREIRE, Paulo. Pedagogia do oprimido. 17. ed. Rio de Janeiro: Paz e Terra, 1987.

GENTILI, Pablo. Pedagogia da exclusão: crítica ao neoliberalismo em educação. São Paulo, Vozes, 1994.

BRASIL. MINISTÉRIO DA EDUCAÇÃO. Plano Nacional da Educação. Lei 10.172/2001. Brasília: MEC, 2001.

Anteprojeto de Lei da Educação Superior. Brasília: MEC, [s. d.]. Portaria Ministerial de 22 de maio de 2006. Brasília: MEC, 2006.

2007 Portaria MEC/SESu 225 de 16 de março de 2007. Brasília: MEC,

PANIZZI, Wrana Maria. A propósito da reforma universitária. Disponível em: <http://www.universia.com.br/materia/materia.jsp?id=3924>. Acesso em: 24 jan. 2007.

SAVIANI, Dermeval. Da nova LDB ao novo Plano Nacional de Educação: por uma outra política educcional. 2. ed. Campinas, SP: Autores Associados, 1999. 